\title{
Opioid Use and Tobacco Smoking in Patients With Rheumatic Diseases
}

\author{
Mohammad Reza Shakibi, ${ }^{1}$ Ali Rahimi Sadegh, ${ }^{2}$ and Nouzar Nakhaee ${ }^{3,}$ \\ ${ }^{1}$ Research Center for Health Services Management, Institute of Futures Studies in Health, Kerman University of Medical Sciences, Kerman, IR Iran \\ ${ }^{2}$ Research Center for Social Determinants of Health, Institute of Futures Studies in Health, Kerman University of Medical Sciences, Kerman, IR Iran \\ ${ }^{3}$ Neuroscience Research Center, Institute of Neuropharmacology, Kerman University of Medical Sciences, Kerman, IR Iran \\ "Corresponding author: Nouzar Nakhaee, Neuroscience Research Center, Institute of Neuropharmacology, Kerman University of Medical Sciences, Kerman, IR Iran. Tel: \\ +98-3412264196, Fax: +98-3412264198, E-mail: nakhaeen@kmu.ac.ir; nakhaeen@yahoo.com
}

Received 2015 February 13; Revised 2015 May 31; Accepted 2015 September 13.

\begin{abstract}
Background: Rheumatic diseases are chronic diseases, which may be associated with severe and debilitating pain. Objectives: The purpose of this study was to examine the prevalence of tobacco and opioid use among rheumatic patients. Patients and Methods: In this cross-sectional study, 1042 patients referred to a major rheumatology clinic of Kerman city, in south east of Iran, were interviewed. Patients were divided into seven groups of disease, including rheumatoid arthritis (330 persons) osteoarthritis (313 persons), systemic lupus erythematosus (149 persons), back pain(146 persons), spondyloarthropathies ( 62 persons), Behcet's disease (25 persons), and scleroderma (17 persons). The questionnaire consisted of demographic variables, disease-related variables (e.g. duration of disease), the severity of pain on the VAS scale and use of opioids and tobacco based on self-reporting. Results: The mean age of the patients was $49.3 \pm 15.0$ years and mean disease duration in the whole sample was $7.1 \pm 5.1$ years. Opium consumption was reported by 104 persons (9.9\%), codeine, by 185 persons (17.7\%), cigarette smoking by 49 persons (4.7\%) and waterpipe smoking by 34 persons (3.3\%).

Conclusions: In this study, codeine consumption is the most frequently used substance. The consumption of opium is not much different from the general population. Also, the rate of cigarette and waterpipe smoking was less than that in the general population. The prevalence of opium use and tobacco smoking was higher in men than in women. There was no significant relationship between type of rheumatic diseases, disease-related variables, and substance use.
\end{abstract}

Keywords: Rheumatic Diseases, Opioid, Tobacco, Waterpipe Smoking, Iran

\section{Background}

Musculoskeletal disorders are amongst the most common diseases in different age groups, which may cause disability, early retirement and job loss (1). Prevalence of rheumatic diseases is different, and osteoarthritis and low back pain are named as the most common rheumatic disease (1). Systemic lupus erythematosus is an autoimmune disease. Its prevalence in US is 15 to 50 cases per 100000 (1). Rheumatoid arthritis is a chronic and multiple system disease. Its prevalence is $0.8 \%$ of the population, and with increasing age, the prevalence increases (1). Patients with rheumatic diseases know pain as one of the most important and challenging outcomes of their disease. Multiple medications to reduce pain and other physical and psychological effects are used. Since the severity of pain is different, some common treatments for pain control may not be enough, and there is need for alternative therapies or compounds (2). Opioids are compounds that can be used to relieve pain (3). The American college of physicians and the American pain society clinical guidelines recommend opioids use in cases of severe pain who have not responded to treatment with NSAID (3).

On the other hand, the opioid abuse (e.g. heroin, opium) in many regions of Asia has increased since 2009. Opioid consumption in Iran is high and according to the UNODC report, its prevalence is about $1.5 \%-3.2 \%$ in the population 15 to 64 years (4). Tobacco use in the $21^{\text {st }}$ century led to 100 million deaths, it is predicted that if current trends continue, it will lead to the death of one billion people in the $21^{\text {st }}$ century (5). However, the percentages of smokers in developed countries show a decreasing trend, but the number of smokers in the world is increasing due to population increases, so that, in 2030 , the number of cigarette smokers, would be two billion people (6). In Iran, the prevalence of smoking use among men and women 19 years and older is $21.2 \%$ and $6.7 \%$, respectively (7).

Several studies have been conducted on the relationship between tobacco smoking and rheumatic diseases. Tobacco use has been proposed as a risk factor for rheumatic diseases, and also in relation to their effect on the duration and severity of the disease, several studies have been conducted (8). In a study conducted in an orthopedic spine clinic, 152 out of the 230 patients were treated with opioids. The results showed that opioids significantly reduced the back pain severity score (9). Few studies have been conducted on the prevalence of opioid use among chronic 
rheumatic patients (10).

\section{Objectives}

Despite the high prevalence of drug abuse in the country, very few studies have been conducted on the prevalence of opioid use among this group of patients. Overall, few studies that have been conducted in this field do not provide useful information owing to a low sample size (10). This study aimed to examine the prevalence of opioid and tobacco use in patients with rheumatic diseases.

\section{Patients and Methods}

In this study, 1042 patients with rheumatic disease referred to the main rheumatology clinic of Kerman city, the capital of the largest province in Iran, were studied consecutively in 2013. After explaining the purpose of the study and obtaining a written informed consent, they were asked to complete the questionnaire. The study protocol was approved by the ethics committee. Each section was read and completed for patients who could not read and write. The reliability and validity of self-report, in terms of doctor-patient relationship, also been demonstrated in the papers. The reliability of ever opium use and duration of opium use had kappa's of 0.96 and 0.74 , respectively. The validity of self-reported opium use was also high (11). The questionnaire contained demographic data including gender, age, education, marital status, disease duration, age of onset and severity of pain. The severity of pain was based on a visual analogue scale (VAS) scale with a score between 0 to 10. Drug use was based on self-reporting and this part of the questionnaire was adopted from previous studies, which its reliability and validity had proven $(12,13)$. The questionnaire was completed by two qualified nurses and the clinical examinations and diagnoses were made by a rheumatologist (first author). Data collection was performed in a private area in the rheumatology clinic. In this study, consumers of tobacco and waterpipe in the past 30 days were considered as a current smoker. Rheumatic diagnosis was based on international standards (1). To understand the variables associated with tobacco and opioid use, multivariate logistic regression was used. Variables entered in the model as independent variables were age, sex, marital status, duration of disease, pain intensity, and type of rheumatic disease. The goodness-of-fit of the model was tested using the Hosmer-Lemeshow test.

\section{Results}

From a total of 1042 patients, 861 cases $(82.6 \%)$ were female. The mean age of the patients was $49.3+15.0$ years.
Also, 822 patients (78.9\%) were married, and 204 (19.6\%) had a university education (Table 1 ).

Patients were divided into seven groups of disease, including rheumatoid arthritis (330 cases), osteoarthritis (313 cases), lupus (149 cases) low back pain (146 cases), spondyloarthropathies (62 cases), Behcet's disease (25 cases), and scleroderma (17 cases). The mean ( \pm SD) disease duration in the whole sample was $7.1 \pm 7.1$ years. On average, the intensity of pain was $6.1 \pm 3.1$; the minimum pain intensity was seen in lupus patients $(3.4 \pm 3.5)$ and the maximum pain intensity was reported by patients with low back pain $(7.1 \pm 2.6)$.

In this study, 72 patients (6.9\%) had experienced smoking at least once in their lifetime, and 49 (4.7\%) patients were smokers at present. The mean age at starting smoking was $26.7 \pm 10.9$. Fifty-seven cases (5.5\%), at least once in a lifetime, have consumed waterpipe (Table 2). Table 3 shows the amount and type of substance used in each disease group. Opium consumption was reported by 104 cases (9.9\%), and for methadone and codeine the corresponding figures were $6(0.57 \%)$ and $185(17.7 \%)$, respectively. The mean age of opium onset of use in the whole sample was $42.3 \pm 16.1$ years, and this figure was $43.3 \pm 14.8$ years for codeine. In this study, 5 (4.80\%) out of the 104 subjects who were taking opium, have been consumed opium on the advice of doctors. This figure was 81 cases (43.7\%) for codeine. No one reported heroin or morphine consumption.

Only variable, which remained in the logistic regression model was gender, so that the odds ratio of tobacco and opium use was about 6 times in men, whereas taking codeine was $42 \%$ less likely in men than women (Table 4 ). Drug abuse, including tobacco, opium, and codeine did not show any relationship with rheumatic diseases.

\section{Discussion}

Evaluation of drug use, particularly drug with pain killing properties in rheumatologic setting, for physicians and health policy makers would be informative. This study showed that the prevalence of codeine and opium use was higher compared to tobacco and waterpipe. The main strength of this study was the relatively high sample size, and the main shortcoming of this study was that the sample was not population-based; so, generalization of the results should be done with caution.

In our study, $4.7 \%$ of the patients were current cigarette smokers, and the highest rate of smoking was seen in spondyloarthropathy patients (12.9\%), and the lowest rate was amongst lupus patients (2.0\%). Comparing to Iranian general population, in which for men and women over 19 years, respectively, $21.2 \%$ and $6.7 \%$ are current smokers (7), the rate of smoking was lower. This could be due to the fact 
Table 1. Background Variables of Rheumatic Patients $(n=1042)$

\begin{tabular}{|c|c|c|c|c|c|c|}
\hline \multirow[t]{2}{*}{ Disease } & \multirow[t]{2}{*}{ No. of Subjects } & \multirow[t]{2}{*}{ Age, $y^{a}$} & \multicolumn{2}{|c|}{ Gender $^{\mathbf{a}}$} & \multirow[t]{2}{*}{ Disease Duration $^{b}$} & \multirow[t]{2}{*}{ Pain Severity $^{b}$} \\
\hline & & & Male & Female & & \\
\hline Rheumatoid arthritis & 330 & $48.9(14.3)$ & $49(14.8)$ & $281(85.2)$ & $8.5(8.1)$ & $6.1(3.0)$ \\
\hline Osteoarthritis & 313 & $59.0(10.7)$ & $39(12.5)$ & $274(87.5)$ & $6.1(6.0)$ & $7.0(2.5)$ \\
\hline Low back pain & 146 & $50.6(14.2)$ & $33(22.6)$ & $113(77.4)$ & $5.7(6.9)$ & $7.1(2.6)$ \\
\hline Spondyloarthropathy & 62 & $39.0(12.1)$ & $33(53.2)$ & $29(46.8)$ & $8.1(8.2)$ & $5.5(3.3)$ \\
\hline Behcet's syndrome & 25 & $39.5(11.4)$ & $12(48.0)$ & $13(52.0)$ & $9.0(7.7)$ & $5.0(3.4)$ \\
\hline Scleroderma & 17 & $39.4(12.8)$ & $3(17.6)$ & $14(82.4)$ & $7.4(7.7)$ & $4.2(3.3)$ \\
\hline Total & 1042 & $49.3(15.0)$ & $181(17.4)$ & $861(82.6)$ & $7.1(7.1)$ & $6.1(3.1)$ \\
\hline
\end{tabular}

${ }^{\mathrm{a}}$ Values are presented as No. (\%).

${ }^{\mathrm{b}}$ Values are presented as mean (SD).

Table 2. Tobacco Use Among Rheumatic Patients $(n=1042)$

\begin{tabular}{|c|c|c|c|c|c|c|}
\hline \multirow[t]{2}{*}{ Disease } & \multicolumn{3}{|c|}{ Cigarette } & \multicolumn{3}{|c|}{ Waterpipe } \\
\hline & Ever Smoking a & Current Smoking ${ }^{a}$ & Age of Onset ${ }^{b}$ & Ever Smoking a & Current Smoking ${ }^{\text {a }}$ & Age of Onset ${ }^{b}$ \\
\hline Rheumatoid arthritis & $18(5.5)$ & $12(3.6)$ & $23.9(8.1)$ & $20(6.1)$ & $14(4.2)$ & $30.3(3.6)$ \\
\hline Osteoarthritis & $23(7.3)$ & $9(2.9)$ & $33.1(14.0)$ & $15(4.8)$ & $8(2.6)$ & $42.7(18.1)$ \\
\hline Low back pain & $15(10.3)$ & $14(9.6)$ & $25.8(6.9)$ & $6(4.1)$ & $5(3.4)$ & $34.6(14.3)$ \\
\hline Systemic lupus erythematous & $4(2.7)$ & $3(2.0)$ & $18.0(2.5)$ & $10(6.7)$ & $5(3.4)$ & $21.1(5.8)$ \\
\hline Spondyloarthropathy & $8(12.9)$ & $8(12.9)$ & $23.6(6.2)$ & $4(6.5)$ & $1(1.6)$ & $26(5.3)$ \\
\hline Behcet's syndrome & $3(12.0)$ & $2(8.0)$ & $16.3(5.1)$ & $1(4.0)$ & $1(4.0)$ & 20.0 \\
\hline Scleroderma & $1(5.8)$ & $1(5.8)$ & 35.0 & $1(5.9)$ & $0(0.0)$ & 31.0 \\
\hline Total & $72(6.9)$ & $49(4.7)$ & $26.7(10.9)$ & $57(5.5)$ & $34(3.3)$ & $31.9(15.9)$ \\
\hline
\end{tabular}

${ }^{\mathrm{a}}$ Values are presented as No. (\%).

${ }^{\mathrm{b}}$ Values are presented as mean (SD).

that, in our study, the number of women was more than men. Another factor that must be considered is doctors' advice against cigarette smoking. Also, waterpipe smoking was 3.3\%, which was less than Sarraf-Zadegan et al.'s study, in which the rate of smoking among the general population was 7.2\% (7). This finding may be due to the high percentage of women in our study, and also waterpipe can be cited as an emerging drug among youth and early adolescents. In addition, cigarette and waterpipe smoking did not show a significant relationship.

Regarding opioid use, the highest prevalence of daily consumption was seen in patients with Behcet's syndrome (16\%) and then, spondyloarthropathies with a rate of $9.7 \%$. The lowest daily consumption of opium was seen in lupus patients with a rate of $3.4 \%$. Concerning the codeine use, the highest daily consumption was associated with Behcet's syndrome and scleroderma, and the lowest con- sumption was associated with spondyloarthropathies. In a study, which was done in 2004 in Kerman city to investigate the prevalence of opioid use among male general population, $11.5 \%$ of the 1120 urine samples collected were positive for opioids (14). Considering the prevalence of $8.25 \%$ in our study, and since our samples included both sexes we can regard the two prevalence figures roughly similar. As a whole, the prevalence of codeine and opium consumption among rheumatic patients was more than cigarette and waterpipe smoking, which may be due to the pain-killing characters of opioids and physicians' advice against tobacco smoking. In one study, the review found that the prevalence of opioid use among patients with chronic low back pain may reach as high as $43 \%$ (15). In a study conducted on 160 rheumatic patients (80 males and 80 females) in 2005 in Shiraz, 31.3\% were opium users and 6.5\% were nicotine smokers, which were higher than the values 
Table 3. Opium and Codeine Use Among Rheumatic Patients ( $n=1042)$

\begin{tabular}{|c|c|c|c|c|}
\hline \multirow[t]{2}{*}{ Disease/Drug } & \multicolumn{3}{|c|}{ Frequency of Use ${ }^{a}$} & \multirow[t]{2}{*}{ Mean Age of Onset } \\
\hline & Every Day & 1- 2 times/wk & Nearly Once Monthly & \\
\hline \multicolumn{5}{|c|}{ Rheumatoid arthritis } \\
\hline Opium & $12(3.6)$ & $10(3.0)$ & $8(2.4)$ & $42.5(14.9)$ \\
\hline Codeine & $33(10.0)$ & $21(6.3)$ & $8(2.4)$ & $45.6(12.6)$ \\
\hline \multicolumn{5}{|l|}{ Osteoarthritis } \\
\hline Opium & $24(7.6)$ & $10(3.2)$ & $2(0.6)$ & $49.3(15.7)$ \\
\hline Codeine & $30(9.6)$ & $21(6.8)$ & $8(2.6)$ & $49.1(15.0)$ \\
\hline \multicolumn{5}{|l|}{ Low back pain } \\
\hline Opium & $8(5.5)$ & $4(2.7)$ & $4(2.7)$ & $43.1(16.1)$ \\
\hline Codeine & $9(6.2)$ & $10(6.9)$ & $5(3.7)$ & $43.9(15.4)$ \\
\hline \multicolumn{5}{|c|}{ Systemic lupus erythematous } \\
\hline Opium & $5(3.4)$ & $2(1.4)$ & $2(1.3)$ & $30.4(8.4)$ \\
\hline Codeine & $12(8.1)$ & $10(6.7)$ & $5(3.4)$ & $30.1(11.0)$ \\
\hline \multicolumn{5}{|c|}{ Spondyloarthropathy } \\
\hline Opium & $6(9.7)$ & 0 & $2(3.2)$ & $27.8(10.3)$ \\
\hline Codeine & $3(4.8)$ & $2(3.2)$ & 0 & $39.4(14.5)$ \\
\hline \multicolumn{5}{|c|}{ Behcet's syndrome } \\
\hline Opium & $4(16.0)$ & 0 & 0 & $26.5(13.8)$ \\
\hline Codeine & $3(12.0)$ & 0 & 0 & $29.3(5.1)$ \\
\hline \multicolumn{5}{|l|}{ Scleroderma } \\
\hline Opium & $1(5.9)$ & 0 & 0 & 54.0 \\
\hline Codeine & $2(11.8)$ & $1(5.9)$ & $2(11.8)$ & $29.8(7.5)$ \\
\hline \multicolumn{5}{|l|}{ Total } \\
\hline Opium & $60(5.75)$ & $26(2.49)$ & $18(1.72)$ & $42.3(16.1)$ \\
\hline Codeine & $92(8.82)$ & $65(6.23)$ & $28(0.26)$ & $38(8.3)$ \\
\hline
\end{tabular}

${ }^{\mathrm{a}}$ Values are presented as No. (\%).

${ }^{\mathrm{b}}$ Values are presented as mean (SD).

obtained in our study. The lower values obtained in our study may be, to some extent, due to the difference in the sex composition of the two studies.

In studies conducted on nonrheumatic patients, different results have been obtained. In a study conducted on 600 cardiac patients, who were candidates for surgery, in north of Iran in 2007 , only $5 \%$ were dependent on opium (16). In our study, the most abused substance among all patients was codeine, and no significant relationship was found between pain intensity and duration of illness and opium and tobacco consumption. The only variable that remained in the logistic model was male sex, and smoking of opium, unlike codeine was higher in males. Since there was no association between pain intensity and duration of rheumatic disease and opium and codeine consump- tion, the two drugs with pain relief characteristics, it can be concluded that opiates consumption in the rheumatic patients in Iran is related to cultural and historical contexts rather than clinical characteristics.

In conclusion, in rheumatic patients the prevalence rate of tobacco and opioids use was lower compared to the general population.

\section{Footnotes}

Authors' Contribution: Mohammad Reza Shakibi: idea, proposal development, clinical examination, and manuscript drafting; Ali Rahimi Sadegh: proposal development, data gathering, and manuscript drafting; Nouzar 
Table 4. Multivariate Logistic Regression of Correlates of Opioids and Tobacco Use by Patients with Rheumatic Diseases

\begin{tabular}{|c|c|c|c|}
\hline Substance/Variable & $\begin{array}{l}\text { Adjusted Odds } \\
\text { Ratio }\end{array}$ & $\begin{array}{l}\text { 95\% Confidence } \\
\text { Interval }\end{array}$ & PValue \\
\hline \multicolumn{4}{|l|}{ Tobacco } \\
\hline Gender & & & $<0.001$ \\
\hline Male & 6.45 & $4.21-10.82$ & \\
\hline Female & 1 & - & \\
\hline \multicolumn{4}{|l|}{ Opium } \\
\hline Gender & & & $<0.001$ \\
\hline Male & 5.97 & $3.51-10.16$ & \\
\hline Female & 1 & - & \\
\hline Age, $y$ & 1.04 & $1.02-1.06$ & $<0.001$ \\
\hline \multicolumn{4}{|l|}{ Codeine } \\
\hline Gender & & & 0.029 \\
\hline Male & 0.58 & $0.36-0.96$ & \\
\hline Female & 1 & - & \\
\hline Education & & & 0.012 \\
\hline College & 1 & - & \\
\hline Others & 1.82 & $1.14-2.90$ & \\
\hline
\end{tabular}

Nakhaee: proposal development, statistical analysis, and manuscript drafting.

Funding/Support: This study was financially supported by Kerman neuroscience research center.

\section{References}

1. Gabriel SE, Michaud K. Epidemiological studies in incidence, prevalence, mortality, and comorbidity of the rheumatic diseases. Arthritis Res Ther. 2009;11(3):229. doi: 10.1186/ar2669. [PubMed:19519924].

2. Portenoy RK, Foley KM. Chronic use of opioid analgesics in nonmalignant pain: report of 38 cases. Pain. 1986;25(2):171-86. [PubMed: 2873550].
3. Chou R, Qaseem A, Snow V, Casey D, Cross JT Jr., Shekelle P, et al. Diagnosis and treatment of low back pain: a joint clinical practice guideline from the American College of Physicians and the American Pain Society. Ann Intern Med. 2007;147(7):478-91. [PubMed: 17909209].

4. United Nation . United Nations Office on Drugs and Crime.; 2009. World Drug Report 2009; .

5. Shafey O, Eriksen M, Ross H. The tobacco atlas. 3rd ed. Atlanta: American Cancer Society 2009; .

6. World Health Organization . Geneva, Switzerland: World Health Organization; 2008. Fresh and alive: Mpower, WHO report on the global tobacco epidemic;

7. Sarraf-Zadegan N, Boshtam M, Shahrokhi S, Naderi GA, Asgary S, Shahparian $\mathrm{M}$, et al. Tobacco use among Iranian men, women and adolescents. Eur J Public Health. 2004;14(1):76-8. [PubMed: 15080396].

8. Ruiz-Esquide V, Gomez-Puerta JA, Canete JD, Graell E, Vazquez I, Ercilla MG, et al. Effects of smoking on disease activity and radiographic progression in early rheumatoid arthritis. J Rheumatol. 2011;38(12):25369. doi: 10.3899/jrheum.110410. [PubMed: 22045838].

9. Mahowald ML, Singh JA, Majeski P. Opioid use by patients in an orthopedics spine clinic. Arthritis Rheum. 2005;52(1):312-21. doi: 10.1002/art.20784. [PubMed: 15641058].

10. Ahmadi J, Pridmore S. Substance Use Disorders in Rheumatic Patients. German J Psychiatry. 2005;5:66-9.

11. Abnet CC, Saadatian-Elahi M, Pourshams A, Boffetta P, Feizzadeh A, Brennan $\mathrm{P}$, et al. Reliability and validity of opiate use self-report in a population at high risk for esophageal cancer in Golestan, Iran. Cancer Epidemiol Biomarkers Prev. 2004;13(6):1068-70. [PubMed: 15184266].

12. Ziaaddini $\mathrm{H}$, Sharifi A, Nakhaee N, Ziaaddini A. The prevalence of at least one-time substance abuse among kerman pre-university male students. Addict health. 2010;2(3-4):103.

13. Sabahy AR, Divsalar K, Bahreinifar S, Marzban M, Nakhaee N. Waterpipe tobacco use among Iranian university students: correlates and perceived reasons for use. Int J Tuberc Lung Dis. 2011;15(6):844-7. doi: 10.5588/ijtld.10.0744. [PubMed: 21575309].

14. Nakhaee N, Divsalar K, Meimandi MS, Dabiri S. Estimating the prevalence of opiates use by unlinked anonymous urine drug testing: a pilot study in Iran. Subst Use Misuse. 2008;43(3-4):513-20. doi: 10.1080/10826080701772348. [PubMed: 18365947].

15. Martell BA, O'Connor PG, Kerns RD, Becker WC, Morales KH, Kosten TR, et al. Systematic review: opioid treatment for chronic back pain: prevalence, efficacy, and association with addiction. Ann Intern Med. 2007;146(2):116-27. [PubMed: 17227935].

16. Azarasa M, Azarfarin R, Changizi A, Alizadehasl A. Substance use among Iranian cardiac surgery patients and its effects on short-term outcome. Anesth Analg. 2009;109(5):1553-9. doi: 10.1213/ANE.ob013e3181b76371. [PubMed: 19843794]. 